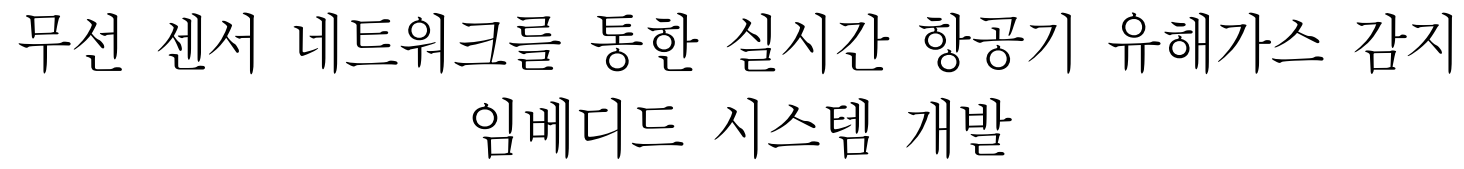

\title{
Development of Real time Aircraft harmful gas detecting Emebedded system through wireless sensor network
}

\author{
최원혁*, 지민석** \\ Won-Huyck Choi*, Min-Seok Jie* \\ 요 약
}

본 논문에서는 최근 정보통신 기술의 발전으로 인해 IT와 전통산업 간의 융합 기술을 적용한 응용서비스가 대두되고 이를 이용한 유해가스 감지 응용서비스로 자동 및 원격으로 항공기내환경을 모니터링하여 제어하고 유지·관리할 수 있는 무선 센서 네트워크기반의 유해가스환경 감지시스템에 대해 활발하게 논의되고 있다. 본 논문에서는 유해가스를 측정하여 모니터링 장치로 전송하는 무선 센서 네트워크센서노드, 센서노드로부터 수집 한 데이터를 취합하고 디스플레이 및 서버로 환경정보를 전송하는 모니터링 관리장치와 또한 원격 모니터링을 위한 $\mathrm{PC} /$ 스마트폰 기반 사용자 운용프로그램으로 구성하여, 항공기내에서 발생하는 유해가스 가스를 측정하고, 모니터링하는 무선 센서 네트워크기반의 실시간 모니터링 시스템을 설계하고 구현한다.

\section{Abstract}

In this paper, with the development of Information technology, application service between IT and traditional industry has been on the rise. And there are many on-going discussions actively regarding the Air quality system based on wireless sensor network which monitor and control the aircraft environment automatically and manually with the application service of detecting harmful gas. In this paper, operation program constitute the administrator monitoring device, which collects data from sensor node of wireless sensor network and sensor node and transmits environment information to display and server. Also for remote monitoring, user operation program constitutes based on PC/smartphone. Under this, the harmful gas which is made in aircraft life is measured. Real time monitoring system based on wireless sensor network is designed and realized.

Key words : Smartphone, Wireless sensor network, Energy, Electric power, Real time monitoring system

\section{I. 서 론}

최근에 충북 가스 누출사고, 반도체공장 불산 가 스 누출사고, 대형 화학 공장 불산 가스 누출사고 포
함 대형 누출 사고가 2013년에 들어서 세 번이나 있 었고 매년 크고 작은 가스 사고들이 일어난다. 화학 물질이나 유해가스는 한 번의 사고가 대형사고로 이 어지기 때문에 철저한 관리가 필요하고 사고 후에는

* 두원공과대학 (Special Study of Smart Network, Doowon Technical University College )

** 한서대학교 항공전자공학과 (Dept. of Avionics Engineering, Hanseo University)

· 제1저자 (First Author) : 최원혁(Won-Huyck Choi, tel : +82-31-935-7212, email : rbooo@korea.com)

· 접수일자 : 2013년 10월 7일 · 심사(수정)일자 : 2013년 10월 7일 (수정일자 : 2013년 12월 13일) · 게재일자 : 2013년 12월 30일 http://dx.doi.org/10.12673/jkoni.2013.17.6.672 
빠른 초기대응이 필요하다. 대응 조치를 위해서는 시간별 유해가스 농도의 실시간 측정이 중요하다. 최 근 여러 종류의 유해환경 가스와 항공기내의 밀폐화 에 따라 인체에 치명적인 가스 농도가 허용 노출기준 을 초과할 수 있다[4]. 인체에 치명적으로 발생하는 주된 유해가스는 탄화수소, 황화수소불소화합물은 유동성 가스로 무색이며, 낮은 사람의 눈, 폐, 피부 등을 자극한다. 메탄가스는 항공기내부의 바닥 표면 에 깔려 있다. 항공기내부에서 큰 피해를 줄 수 있다. 그러므로 허용 기준치 이상의 유해가스 발생 시 신속 한 환기와 발생 유해가스의 종류와 농도에 따른 피해 예상과 대처방안을 마련하여 인적 피해와 기업의 생 산성 향상 문제를 해결한다. 또한 각종 환경문제를 해결할 수 있을 것이다[1].

이를 위하여 최근 언제 어디서나 다양한 센서로 제공되는 모든 서비스를 구현하고, 어떤 단말 장치 또는 디바이스로도 콘텐츠를 이용할 수 있는 유비쿼 터스 환경의 정보통신 기술의 발전으로 인한 IT와 전 통산업 간의 융합 기술을 적용한 응용서비스가 대두 되고, 이를 이용한 유해가스 감지 응용서비스로 자동 및 원격으로 기내 환경을 모니터링하여 제어하고 유 지·관리할 수 있는 무선 센서 네트워크기반의 유해가 스환경 감지시스템에 대해 활발하게 논의되고 있다 [5].

본 논문에서는 유해가스를 측정하여 모니터링 장 치로 전송하는 무선 센서 네트워크센서노드, 센서노 드로부터 수집한 데이터를 취합하고 디스플레이 및 서버로 환경정보를 전송하는 모니터링 관리 장치와 또한 원격 모니터링을 위한 $\mathrm{PC} /$ 스마트폰 기반 사용 자 운용프로그램으로 구성하여, 일상 환경에서 발생 하는 유해가스 가스를 측정하고, 모니터링하는 무선 센서 네트워크기반의 실시간 모니터링 시스템을 설 계하고 구현한다.

II. 관련연구 및 무선 센서 네트워크센서노드 구현

무선 센서네트워크를 이용한 유해가스 감시 시스 템을 이용하여 항공기내의 내외부에 설치하여 실시
간으로 유해가스영역 안팎을 감시하여 관리자에게 통보하는 시스템을 말한다. 이를 위하여 고속의 유해 가스 감지 센서, 무선 센서네트워크, 감지제어시스템, 모니터링 시스템이 필요하다. 유해감지시스템에서 가장 중요한 부분은 센서로 감지된 센서 값을 무선 센서 네트워크로 전송해 주는 부분이다 센서를 실시 간으로 전송하기 위해서는 가볍고 손상이 비교적 적 은 무선 센서네트워크 기술이 필요하다.

\section{2-1 센서네트워크 기술}

무선 센서 네트워크는 어느 곳에나 부착된 태그와 센서로부터 사물 및 환경 정보를 감지, 저장, 가공하 여 인터넷을 통해 전달하는 기술로 거의 모든 인간 생활에 활용하는 것을 목적으로 한다.

무선 센서 네트워크 서비스의 경우, 현재는 건물 의 안전과 같은 공공의 목적, 적지 정찰과 같은 군용 목적, 생태계나 환경오염의 관측과 같은 과학적인 목 적에 주로 응용 서비스 기술이 개발되고 있으나, 점 차 댁내 안전, 편리성, 나아가서는 인간의 생체에 응 용될 수 있는 상황 인지의 지능형 서비스로 발전할 전망이다.

또한 농업, 광업, 어업, 상업, 건설 등 산업 전반의 생산 공정에 무선 센서 네트워크를 활용함에 따라 원 자재 관리, 생산 자동화 및 상품이력 관리로 생산성 및 효율성 증대에 기여하고 환경, 기상, 생태계, 재해 예측 및 방재, 시설제어, 교통정보 및 제어, 물류, 가 정/사무자동화, 의료, 복지, 교육, 방범, 보안 등 광범 위한 분야에 무선 센서 네트워크의 적용으로 국민의 복지 수준이 향상될 것으로 기대된다[6].

센서노드는 무선 센서 네트워크를 구성하는 가장 기본적인 요소로 기존 RFID 기술에 비하여 큰 장점 은 주위 환경을 모니터링 하여 최적의 네트워크 구성 및 기존의 유무선 센서 네트워크 통신 기술을 이용하 여 사용자가 원하는 네트워크 구성이 가능하다는 것 이다. 


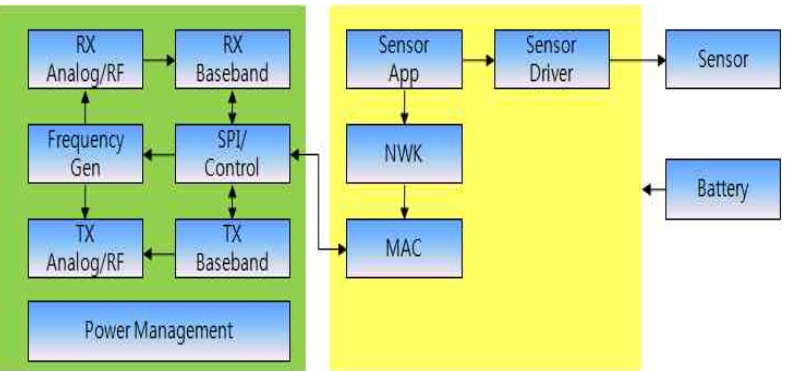

그림 1. 센서노드의 기본 구성 요소

Fig. 1. the basic configuration of sensor node

센서노드의 구성은 주로 제어부(MCU), 무선 센서 네트워크통신부, 센서부 및 전원부로 구성되며, 현재 선보여지고 있는 응용 서비스에서의 센서노드는 다 수의 노드를 광범위한 환경에서 분산 배치하여 이용 되어 노드의 전원을 자주 교환하는 것이 어렵기에 때 문에 저전력 센서노드 개발이 요구된다[3].

또한 응용 서비스에 따라 노드의 설치 용이성이 고려되므로 센서노드의 소형화와 경량화가 필수적이 다. 그림 1 은 센서노드의 기본 구성 요소를 보인 것 이다. 무선 센서 네트워크 시스템에서는 수신도 송신 처럼 에너지를 소모한다. 이러한 전력소모는 배터리 원으로 장시간 동작해야 하는 센서망에서는 치명적 이다. 무선 센서 네트워크시스템 입장에서 에너지 소 모를 야기하는 요소를 살펴보면 다음과 같다.

- 충돌(Collision): 2 개 이상의 패킷이 한 채널에 동 시에 전송되어 발생하여 전송 패킷에 오류가 발생하 여 재전송으로 인한 쓸데없는 에너지 낭비 초래

- Overhearing: 다른 노드로 가는 패킷을 쓸데없이 수신하여 에너지 낭비 초래

- Idle Listening: 아무도 송신중이 아닌데도 쓸데없 이 수신 대기하면서 에너지 낭비 초래

- Protocol Overhead: RTS/CTS/SYNC 등의 제어메 시지 송수신에 의한 에너지 낭비 초래

이러한 에너지소모 요소를 고려하여 센서노드용 $\mathrm{MAC}$ 은 자신이 송신하거나 수신할 때만 깨어나고, 나머지 시간에는 sleep하여 전원을 절약하는 기능을 기본적으로 지원한다. 그림 2처럼 비컨 메시지를 통 해 Active/InActive 구간의 길이와 $\mathrm{CAP}, \mathrm{CFP}$ 등을 설정 하게 된다.

InActive 기간이 길고, beaconinterval이 길수록 노 드가 sleep하는 시간이 길어지기 때문에 노드의 수명
은 늘어난다. 하지만 패킷 전달에 필요한 시간이 늘 어나고, 실시간으로 급하게 전송해야 하는 데이터의 경우 불리할 수 있다.

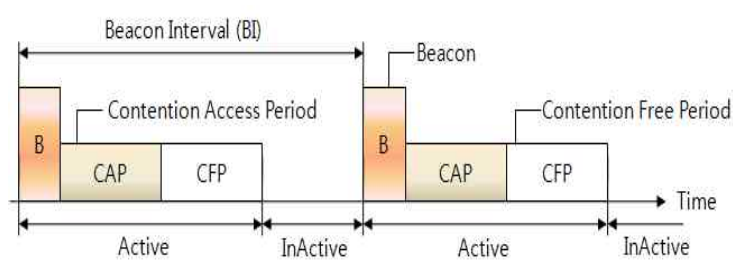

그림 2. 센서 네트워크 사이클

Fig. 2. Active/In active section

계층구조를 갖는 통신 프로토콜은 최적화된 성능 을 보장하지는 않는다. 특히, 센서네트워크와 같이 에너지원, 계산 능력, 메모리 용량 등이 극히 제한된 시스템의 경우는 모듈기반의 계층구조로는 얻고자하 는 성능에 한계를 가질 수 있으며, 사용 가능한 에너 지원이 극히 제한된 센서네트워크에서는 효율적인 배터리 사용이 필요하다. 이러한 제약조건을 가진 센 서노드에 잘 알려진 OSI 모델의 프로토콜 계층을 그 대로 사용하기는 현실적으로 불가능하다. 계산에 의 한 에너지 소비보다 신호의 전송에 소요되는 에너지 가 월등히 큰 센서네트워크에서는 효율적인 전송방 법의 설계가 중요하다[7].

유선 통신과 달리 무선 센서 네트워크 통신 채널 은 다수의 신호전달 경로에 의해 생기는 채널 페이딩 과 이동성에기인한 도플러 효과 등에 의해 통신용량 과 비트에러가 시변적인 특징을 갖는다. 채널 코딩, 변/복조 신호처리, 에러 제어 방법 등을 통해 물리적 통신 채널의 성능을 향상시킬 수 있지만, 고정된 통 신용량을 갖거나 신뢰할 수 있는 링크 연결 및 유지 를 보장하기는 불가능하다. 만족할만한 네트워크 성 능을 제공하기 위해 MAC, routing, transport 계층의 프로토콜은 물리계층과 상호 협조적으로 작동해야 할 필요가 있다[2].

\section{2-2 무선 센서 네트워크센서노드 제작}

센서측정값에 대한 물리적 매칭을 위해 센서출력 은 선형적인 것이 좋다. 이를 위해 대부분의 센서는 선형성을 보장하기 위한 보정알고리즘이 하드웨어적 
으로 구현되어 있다. 가스에 대한 상용센서는 현재 산업에서 많이 사용되고 있으며, 센서출력값을 물리 적 수치로 교정하기위한 일반화 식이 주어진다. 또한 이러한 센서들은 공기 중 복합적으로 존재하는 이종 의 가스에 대한 영향을 적게 받는다.

하지만 본 연구에서 선택한 저전력 반도체식 상용 가스센서는 이종의 가스에도 반응을 보이며, 센서출 력의 선형성 또한 보장하지 않는다.

본 시스템은 MN-403 센서를 이용하여 유해 가스 를 식별하고, 식별한 가스의 농도를 추정하는 알고리 즘이 탑재된 무선 가스센서노드의 시스템구성을 보 여준다.

각종센서 디바이스드라이버를 설계하기 위해IAR 사의 컴파일러, 디버거, MSP-FET430 에뮬레이터 등 을 이용하여 개발환경을 구축하고, 센서 디바이스 구 동프로그램을 작성하고 테스트한다. 제작한 센서보 드를 지그비보드와 결합하고 이렇게 구현한 최종 무 선 센서 네트워크센서노드에 작성한 모든 디바이스 구동 프로그램과 제어 프로그램을 내장하여 보드 상 호간에 하드웨어적인 문제가 발생하지 않는지 확인 하고 수정한다. 그림 3은 메탄가스를 측정하기 위해 구현한 가스센서모듈이다.

스마트 유해가스 측정 시스템은 Atmel사의 ATmega 128을 사용하여 전체 장치들을 제어하였다. 초기에는 우리 팀이 주로 사용했던 8 bit 마이크로컨 트롤러의 대표격인 ATmega 128을 사용 하였다. 이들 AVR 마이크로컨트롤러 계열은 같은 구조의 Core를 사용하고 있어서 기본구조 및 명령어가 동일하며 사

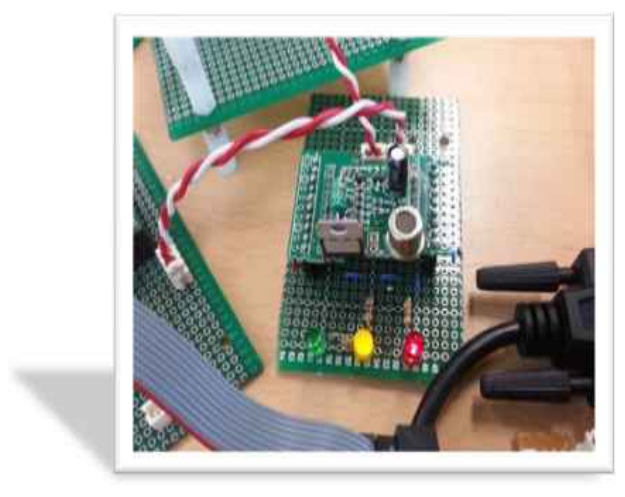

그림 3. $\mathrm{MN}-403$ 가스센서모듈

Fig. 3. MN-403 Gas sensor System

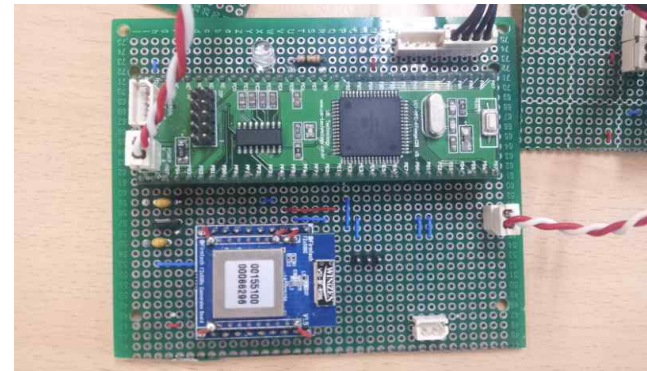

그림 4. ATmega128

Fig. 4. ATmega128 System

용법 또한 매우 유사하다.

ATmega128은 8비트 RISC(Reduced Instruction Set Computer) 구조의 AVR Core를 가지는 마이크로컨트 롤러로써 대부분의 명령어를 Single Cycle로 수행한 다[6][7]. 그림 4는 ATmega128 모듈이다.

유해가스감지 시스템의 칩 내부의 ATmega128은 발진회로, GPIO 입출력 포트, Timer/Counter, RTC(Real Time Clock), USART(Universal Synchronous Asynchro nous Receiver and Transmitter)와 SPI(Serial Peri pherial Interface), PWM(Pulse Width Modulation), ADC(Analog to Digital Converter), Analog 비교기, Watchdog Timer, $\mathrm{I} 2 \mathrm{C}$ 가 있으므로 $\mathrm{CPU}$ 칩 하나로 시스 템을 위치감지 시스템은 하드웨어 특성상 일정 조건 에서만 데이터를 받는 구조가 아니고 일정시간마다 주기적으로 데이터를 받는 형태이므로 polling 방식이 적합하다. 본 시스템에서는 가스정보를 실시간으로 $7 \mathrm{byte}$ 씩 끊어서 여덟 번을 보내고 마지막 한번은 감 지제어 장치로 보낸 다음 이를 다시 반복한다. 그림 5 는 센서네트워크 통신부이다.

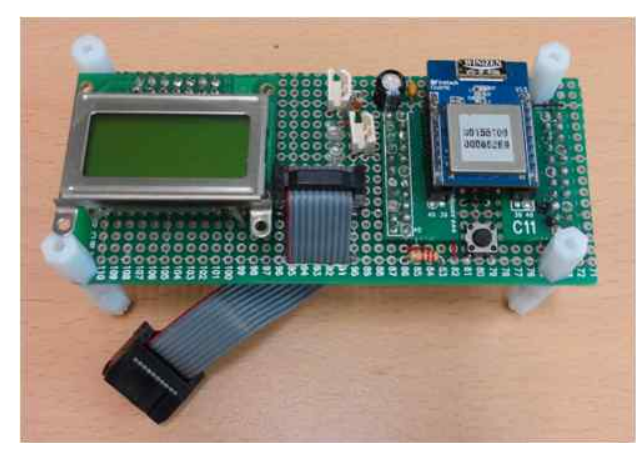

그림 5. 무선 센서 네트워크 시스템 Fig. 5. Wireless Sensor Network System 


\section{III. 유해가스 감지 모니터링 시스템 구현}

제안하는 무선 센서 네트워크기반 유해가스 모니 터링 시스템은 무선 센서 네트워크와 가스센서노드 를 통해 기내외부 환경상태 정보를 수집하여 사용자 에게 항공기내의 온도, 습도, 유해가스 상태를 현장 및 원격지에서 효율적으로 모니터링할 수 있도록 지 원하는 시스템이다. 시스템 구성요소는 무선 센서 네 트워크가스센서노드, 모니터링관리장치, 관리서버, $\mathrm{PC}$ 기반 사용자 운용프로그램, 스마트폰기반 사용자 운용프로그램으로 이루어진다.

\section{3-1 모니터링관리장치}

모니터링 관리 장치는 각 무선 센서 네트워크센서 노드와 무선 가스센서노드로부터 송신된 데이터를 사용자설정 기준 값과 비교하여 위험상황인지 아닌 지를 판단하고 위험상황발생시 디스플레이장치 화면 상에 위험상황임을 표시하고, 부저를 통하여 소리로 위험상황이나 이상발생을 알려준다. 그리고 원격알람 을 위해 휴대폰을 통하여 등록된 사용자전화번호로 경고 문자를 전송한다. 또한 모니터링 관리 장치는 사 용자가 설정한 일정시간마다 CDMA모뎀을 이용하여 수집한 가스농도정보를 문자로 발송하고, 사용자가 현장외부에서 유해가스를 모니터링 할 수 있도록 웹 을 지원하는 관리서버로 환경정보를 전송한다.

그림 6에서 보인 바와 같이 모니터링 관리 장치는 통신, 가스모터작동, 파워, 디스플레이 블록으로 구 성한다. 통신블록은 모니터링 관리 장치와 각 센서노

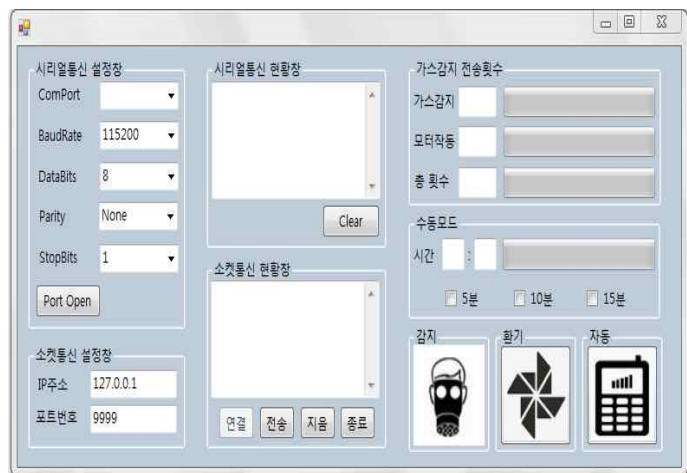

그림 6. 제안한 모니터링 시스템 구성

Fig. 6. Proposed Monitoring System
드간의통신을 위해 무선 센서 네트워크통신을 이용 하고, 서버간의 통신은 지그비통신을 적용하여 구성 하였으며, 설정블록은 사용자가 직접 조작하는 부분 으로 경고 문자를 보낼 전화번호 설정, 측정센서노드 의 종류에 따른 표시장치 설정, 위험상황을 알리기 위해 각 센서노드에서 수집한 환경데이터와 비교하 기 위한 기준 값 설정, 디스플레이블록은 통신이 정 상적으로 이루어진 각 센서노드의 현재 상태와 위험 상황경고 등을 표시하는 부분이다. 이러한 모든 기능 을 수행하기 위해 시스템목적에 적합한 소프트웨어 를 프로그래밍하고, 모든 관련디바이스에 대한 구동 회로를 설계하였다. 또한 API 프로그램은 축적된 환 경정보 데이터를 기간별/시간별로 실시간 환경데이 터를 모니터링하기에 적합하도록 $\mathrm{C \#}$ 프로그램을 이 용하여 개발하였다.

그림 7은 센서측정데이터 변화를 그래프로 확인할 수 있는 창이다. (1) 센서 노드와의 통신을 위한 기본 설정 창, (2)서버와의 소켓통신을 위한 창 ,(3)현재의 작동모드를 확인 할 수 있는 창, (4)가스감지 현황을 확인하고 서버로 감지 값을 전송하기 위한 창, (5)가 스의 감지횟수와 모터작동 횟수를 확인할 수 있는 창, (6)수동모드로 체크를 해놓으면 체크한 시간이 흐 르면 한 번 모터 작동, (8)수동 작동 (9)자동모드로 누 르면 15 분마다 차단기 작동으로 구성되어 있다.

또한 안드로이드 앱을 이용하여 개발한 스마트폰 기반사용자 운용프로그램은 등록된 이동통신망에 접 속하여 인터넷을 통해 관리서버 데이터베이스에 축 적된 환경정보 데이터를 실시간으로 확인할 수 있다.

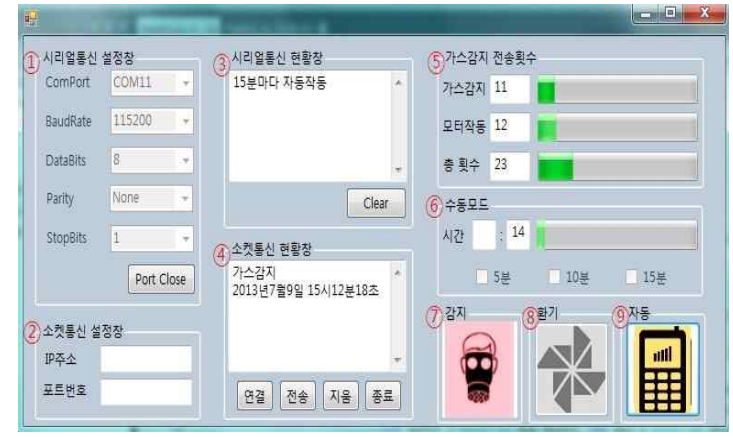

그림 7. 센서측정데이터

Fig. 7. Sensor measurement data 

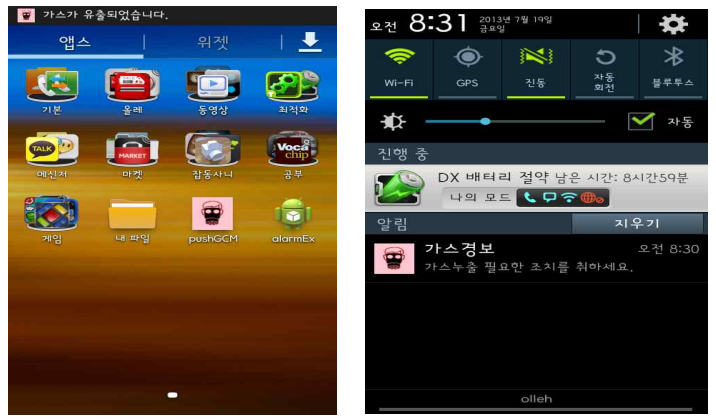

그림 8. 유해가스 정보 측정 시스템

Fig. 8. Smart harmful gas detecting System

\section{IV. 결 론}

유해가스 정보를 주기적으로 수집하여 사용자가 다양한 플랫폼에서 환경상태를 감시하고, 축적된 환 경요인데이터를 통하여 생산품의 질적 향상과 생산 량의 증대를 가지며, 각 환경요소의 위험범위를 지정 하여 범위 초과 시 신속하게 대응하기 위해 사용자에 게 SMS, 경고등, 부저 등을 이용하여 시청각적으로 위험을 알리는 실시간 모니터링시스템을 구현하였 다. 시스템은 온도, 습도, 메탄가스를 측정하기 위한 무선 센서 네트워크가스센서노드, 그리고 센서노드 에서 수집된 정보를 수집, 분석하여 관리서버에 저장 하고 위험상황을 알려주는 모니터링 관리 장치를 연 구개발 구성하였다. 그리고 실시간 원격모니터링을 위한 $\mathrm{PC} /$ 스마트폰기반 사용자 운용프로그램을 구현 하여 사용자중심의 시스템이 되도록 구현하였다.

시스템의 수행성을 검증하기 위해 실험실기반의 가스측정 실험환경을 구축하고 가스실험에서 무선 센 서 네트워크가스센서노드는 각 대상가스별 농도추정 이 가능함을 보였다. 제작한 모든 센서노드와 모니터 링 관리 장치를 실험실환경에 설치하여 각 플랫폼 별 $\mathrm{GUI}(\mathrm{PC}$, 휴대폰, 스마트폰)를 통해 제안한 환경요소 정보를 모니터링 할 수 있었으며, 위험상황 인지 시 경고문자, 경고등, 부저가 잘 수행함을 확인하였다.

\section{Reference}

[1] G.H. Park, G.Y. Oh, K.H. Jung, S.Y. Jung, G.S. Cha, "The Odor Characteristics of Livestock Raising
Facility," Journal of Odor Research and Engineerin g, Vol. 4, No. 4, pp.207-215, 2005.

[2] M.H. Lee, K.E. Eom, H.J. Kang, C.S. Shin, H.Yoe, "Design and Implementation of Wireless Sensor Net work for Ubiquitous Glass Houses,"Proceedings on Seventh IEEE/ACIS International Conference on Co mputer and Information Science, pp.397-400, 2008.

[3] B. Stojkoska, D. Davcev, "Web Interface for Habitat Monitoring Using Wireless Sensor Network," Proceed ings on 2009 Fifth International Conference on Wirele ss and Mobile Communications, pp.157-162, 2009.

[4] C. Ma, Y. Wang, G. Ying, "The Pig BreedingManage ment System Based on RFID and WSN," Proceeding $s$ on 2011 Fourth International Conference on Inform ation and Computing, pp.30-33, 2011.

[5] H. Kim, J.W. Han, Y.S. K, J.N.Choi,“Implementation of Remote Piggery Management System using Wireless Sensor Network," 2011 Summer Conference on Korea Institute ofInformation Technology, pp.550-552, 2011.

[6] D.H. Kwak, T.Jiun-Jian Chang, Pi-Cheng Hsiu,and Tei-WeiK, "Search-Oriented Deployment Strategies for Wireless Sensor Networks", 10th IEEE Internatio nal Symposium on Object and Component-Oriented Real-Time Distributed Computing ISORC'07, pp. 164 -171, 2007

[7] N. Swangmuang, P. Krishnamurty "Location fingerpr int Analyses Toward Efficient Indoor Positioning," Proceedings on IEEE International conference on pe rvasive computing and communications, 2008.

\section{최 원 혁 (Won-Hyuck Choi )}

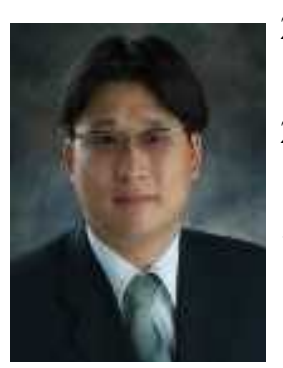
2006년 한국항공대학교대학원 : 항공전자 박사졸업 2008년 현재 : 두원공과 대학 스마트 네트워크 조교수 관심분야 : 임베디드 시스템, 홈 네트워크 
지 민 석 (Jie Min Seok)

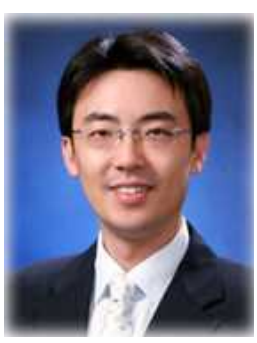

2006년 : 한국항공대학교대학원

항공전자 박사졸업

2008년 현재 : 한서대학교 항공전자

공학과 조교수

관심분야 : 자동제어, 로봇공학 